\title{
Training to Strengthen the Mental Self-boundary (Self-Boundary Awareness Training, SBAT) Results in Greater Mindfulness: How Self-boundary Awareness Increases Mindfulness
}

\author{
Klaus Blaser \\ Centre for applied Boundary Studies \\ Switzerland \\ Jacqueline Buchli-Kammermann \\ Bäumleingasse Practice, Basel, Switzerland
}

\begin{abstract}
42 individuals completed an 8-week course to strengthen the mental self-boundary.

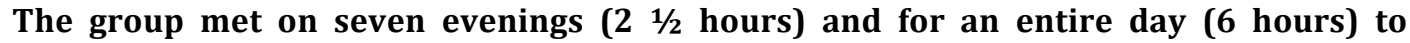
exchange experiences and train the conscious perception of their mental self-boundary in pairs or as a group. At home they carried out a guided imagination exercise every day and kept a diary on specific self-boundary issues. The participants also received theoretical input on the spatial Boundary-Based Awareness Model and had the opportunity to physically experience the various mental perspectives in relation to their own inner mental world and that of others. Participants did not carry out any specific mindfulness exercises at home. Evaluation of FMI and BPS questionnaires completed before and after the training revealed a greatly improved score for the selfboundary domain as well as a significant improvement in the mindfulness score. Below we describe the training in more detail and discuss how self-boundary training could lead to greater mindfulness.
\end{abstract}

Key Words: Boundary-based awareness, Self-boundary, Mindfulness, Consciousness

\section{INTRODUCTION}

In this study, we aim to investigate the effect of a new structured 8-week course to strengthen the mental self-boundary (Self-Boundary Awareness Training, SBAT). On the one hand, we would like to examine the impact of the training on self-boundary awareness by means of a pre- and post-training comparison using the Boundary Protection Scale (BPS-14), and on the other to explore its effect on mindfulness by means of the Freiburg Mindfulness Inventory (FMI).

Although the Boundary based awareness-concept is already extensive described we would like to give a short description here (Blaser 2011, 2012, 2013).

The mental self-boundary determines the location of the focus of attention and thus defines not only the margins of the mental inner space but also the quality of self-perception and perception of others. Thus the mental self-boundary is not only important for self-protection and protection against external stimuli (Freud 1958, Tausk 1992), holding the inner world together (holding environment, Winnicott 1965) and the process of individuation (Stierlin 1978). As illustrated here, the dividing line between the mental inner and outside worlds also defines the mindful mental state (mindfulness) (Blaser 2013). In the spatial "Boundary-Based Awareness" model, three locations of attention can be distinguished, namely the intrapersonal 
space, the intrapersonal space of another person and the extrapersonal space between (interpersonal space). As can be seen in figure 1, the extrapersonal space also contains the intrapersonal space of the other. Similarly, three different foci of attention can be defined. Attention can be directed at one's own inner world (modes 1, 4, 6 and 8), at the inner world of another (modes 3, 7, 8, 9 and 10) or at the external space between (modes 2, 5, 6 and 9) (Blaser 2012).

As illustrated in figure 1 and table 1, there are 10 different interpersonal mental perspectives that can be occupied (Blaser 2012, 2014a). They lead to quite different perceptions of oneself and others. Six modes based on the BBA model (modes 1, 2, 4, 5, 6 and 8) have been investigated neurophysiologically and could be distinguished from each other by means of EEG recordings (Hinterberger 2014) (see table 1).

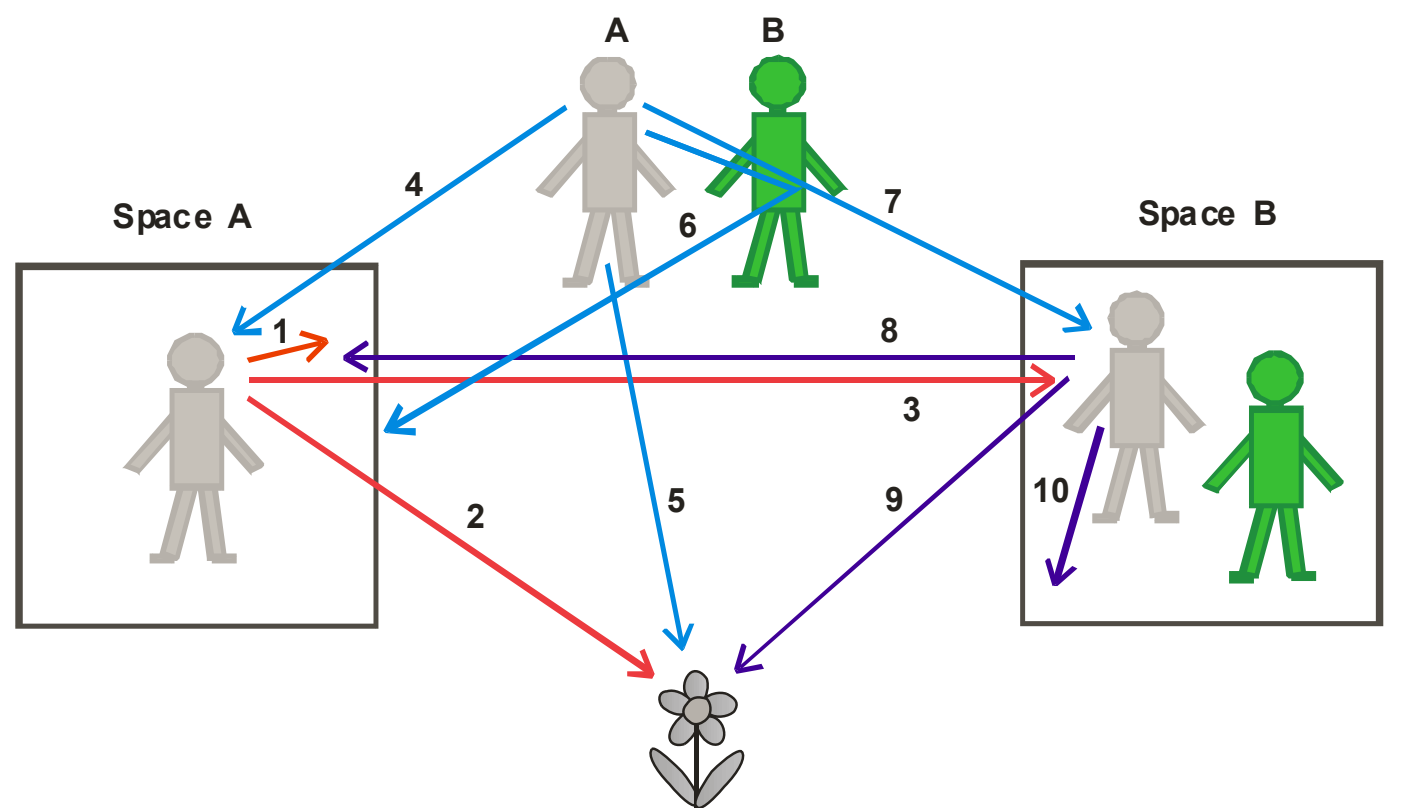

Fig. 1: The 10 interpersonal perspectives that person $A$ can occupy in relation to him/herself and person $B$.

Table 1: Description of the 10 interpersonal mental modes of attention illustrated in figure 2. Note: *These modes could be distinguished from each other electrophysiologically in a neurobiological study.

\begin{tabular}{|l|l|l|l|}
\hline Mode 1 & Mindful interoception* & Mode 6 & Theory of mind* \\
\hline Mode 2 & $\begin{array}{l}\text { Mindful perception of the outside } \\
\text { world* }\end{array}$ & Mode 7 & Theory-theory \\
\hline Mode 3 & $\begin{array}{l}\text { Mindful perception of the inner } \\
\text { world of another, resonance / } \\
\text { compassion }\end{array}$ & Mode 8 & $\begin{array}{l}\text { Empathising with one's own inner } \\
\text { world through the emotional } \\
\text { perspective of another / empathy }\end{array}$ \\
\hline Mode 4 & Cognitive self-perception* & Mode 9 & $\begin{array}{l}\text { Empathising with an outwards } \\
\text { focus through the emotional } \\
\text { perspective of another / empathy* }\end{array}$ \\
\hline Mode 5 & Cognitive perception of an object* & Mode 10 & $\begin{array}{l}\text { Empathising with the inner world } \\
\text { of another / empathy }\end{array}$ \\
\hline
\end{tabular}

In the BBA model, mindful mental states are defined by the location of attention being in the intrapersonal mental inner space. Mindful mental states can therefore have three different orientations of attention, namely inwards from within (mindful introspection, Fig. 1, arrow mode 1), from within towards the extrapersonal space (mindful perception of the outside 
Blaser, K. \& Buchli-Kammermann, J. (2017). Training to Strengthen the Mental Self-boounary (Self-Boundary Awareness Training, SBAT) results in Greater Mindfulness: How Self-Boundary Awareness Increases Mindfulness. Advances in Social Sciences Research Journal, 4(1) 62-71.

world, Fig. 1, arrow mode 2) or from within towards the inner world of another person (resonance, compassion, Fig. 1, arrow mode 3; Blaser 2015, 2013, Gallese 2009, Preston and De Waal 2002).

In the present study, we wish to explore the training effect, with regard to mindfulness and improving awareness of the self-boundary, of an 8-week structured course to strengthen the self-boundary (SBAT), through the use of two questionnaires, the Freiburg Mindfulness Inventory (FMI; Walach 2004) and the Boundary Protection Scale (BPS-14; Blaser 2014).

\section{Mindfulness}

Mindfulness can be defined as paying attention to the present moment in an open, nonjudgemental way (Kabat-Zinn 2003). Historically, mindfulness is seen as being at the heart of Buddhist meditation (Thera 1962), and it occupies a central role in Buddhist teaching (Gunarantana 1992, Hanh 1999). Borkovec (2002) describes mindfulness as follows: "To let go of the illusory future and past to focus on the non-illusory present. It is a focus on the process of the intrinsic qualities and activities." There are various forms of "mindfulness-based interventions", e.g. mindfulness-based stress reduction (MBSR; Kabat-Zinn 1999, 2003), mindfulness-based cognitive therapy (MBCT; Segal 2002), aspects of dialectical behavioural therapy (DBT; Linehan 1993) and acceptance and commitment therapy (ACT; Hayes 1999). Borkovec (2002) describes mindfulness training as "the cultivation of the inner orientation".

\section{Self-Boundary Awareness Training (SBAT)}

SBAT is organised using the basic structure of MBSR (Kabat-Zinn 1999), but is completely different in terms of content. During a period of 8 weeks, the participants meet 7 times (MBSR: 8 times) for $2 \frac{1}{2}$ hours each week and additionally for an entire day (6 hours). At the start of the training the participants are given a CD with guided imagination exercises, and each week only one new exercise is practised daily. The imagination exercises last between 6 minutes (week 6 exercise) and 13 minutes (week 3 exercise). In addition, the participants are given homework each week, which consists of keeping a diary on a specific aspect of the interpersonal attention repertoire. Thus the daily practice period, including the diary writing, is about 20 minutes. For MBSR, in contrast, participants must be prepared to invest 40 minutes each day (Lazar 2005). In SBAT, each weekly $2 \frac{1}{2} 2$-hour meeting starts with an attention exercise, followed by each participant describing shortly their actual mental state. The main part of each meeting consists of exchanging experiences (enquiry) from the imagination exercises practised at home and a discussion of the diary entries. Following that there is theoretical input, whereby the 10 interpersonal forms of attention are discussed (see table 1). On the sixth evening, there is a separate discussion on the various aspects of dissociative mental states (see table 2). Each week the participants are given a handout with a brief summary of the relevant theory. In order to support their spatial understanding of the different locations of attention (the intrapersonal space, the intrapersonal space of another person and the interpersonal space) and the three directions in which attention can be focussed, the metaphor of the "inner garden" for the inner mental world is introduced. With the aid of this metaphor, it is possible to illustrate, for example, the liveliness and mutability of the inner world and the categorisation of emotions, images, experiences and values in the inner space. The garden fence represents the mental self-boundary, and the garden gate stands for the filtering function of the selfboundary, respectively the regulation of interchange with the surrounding world. The garden gate also symbolises the point of access to the outside world as well as the entrance to the inner world. Using this image of a garden, the ten interpersonal forms of attention can be represented visually, and the current location and orientation of one's own attention can be classified in a playful way. With the CD-exercises they learn to consciously move mentally from the outside world into the inner world. This movement is practised in small steps daily in the 
first 3 weeks with guided imagination exercises. The participants learn to approach their "inner garden" little by little. They become aware of their own self-boundary (they learn to perceive themselves from outside) and visualise the "garden gate" through which they can subsequently enter their own inner world.

In SBAT, mentally entering one's own inner space (becoming mindful), moving out into the outside mental space (healthy dissociation) and visiting the inner space of another person (empathy) are all consciously trained. With the garden metaphor it is possible to visualise the flexibility of attention while at the same time physically perceiving the differences.

In table 2, it can be seen that the weekly themes and theory inputs, and the topics of the imagination exercises and diary keeping are not always synchronised. The course was intentionally designed in this manner, in order to promote to the greatest possible extent the desired flexibility of attention.

Table 2: Overview of the theory inputs, imagination exercises and homework in SBAT. *Note: EETIRO stands for emotions, experience, tasks, images, responsibility and opinions (beliefs).

\begin{tabular}{|c|c|c|c|}
\hline & Theory input topic & Imagination exercise topic & Diary keeping topic (homework) \\
\hline Week 1 & $\begin{array}{l}\text { Inner and outside world, EETIRO* } \\
\text { elements, garden metaphor }\end{array}$ & $\begin{array}{l}\text { Looking at the perimeters of the inner world from } \\
\text { outside }\end{array}$ & $\begin{array}{l}\text { Was there a moment today that had } \\
\text { something to do with your self- } \\
\text { boundary? }\end{array}$ \\
\hline Week 2 & Functions of the mental self-boundary & $\begin{array}{l}\text { Looking at the perimeters from outside together } \\
\text { with somebody else ), adapting the self-boundary }\end{array}$ & $\begin{array}{l}\text { Self-perception from the outside world } \\
\text { (meta-position) }\end{array}$ \\
\hline Week 3 & $\begin{array}{l}\text { Mindful interoception, mindful } \\
\text { perception of the outside world }\end{array}$ & $\begin{array}{l}\text { Entering one's own inner world from outside, } \\
\text { looking outside from within, denying someone } \\
\text { access to one's own inner world (saying no) }\end{array}$ & $\begin{array}{l}\text { How and in what situation have you said } \\
\text { "no" today? }\end{array}$ \\
\hline Week 4 & $\begin{array}{l}\text { Mindful perception of the inner world } \\
\text { of another person, resonance, } \\
\text { compassion }\end{array}$ & Looking mindfully inwards from within & $\begin{array}{l}\text { Conscious, bodily perception of an } \\
\text { emotion }\end{array}$ \\
\hline Week 5 & $\begin{array}{l}\text { Location of attention in the outside } \\
\text { world, development of this ability }\end{array}$ & $\begin{array}{l}\text { Giving someone else something nice from one's } \\
\text { inner world. Leaving the inner world and asking to } \\
\text { enter another person's inner world }\end{array}$ & $\begin{array}{l}\text { Mindful perception of another person } \\
\text { (from within) }\end{array}$ \\
\hline Week 6 & Various qualities of being dissociated & $\begin{array}{l}\text { Assigning a new, favourable place in one's own } \\
\text { inner world to one's own unpleasant emotions, } \\
\text { experiences and images }\end{array}$ & $\begin{array}{l}\text { Conscious perception of being } \\
\text { dissociated (being in the outside world } \\
\text { with one's attention) }\end{array}$ \\
\hline Week 7 & $\begin{array}{l}\text { Being with the attention in the } \\
\text { intrapersonal world of the other, } \\
\text { empathy }\end{array}$ & $\begin{array}{l}\text { The participant is free to choose one of the } 6 \\
\text { exercises each day }\end{array}$ & \\
\hline
\end{tabular}

During the entire day of training ( 6 hours), different aspects of perception of the self-boundary of another person, signalling one's own self-boundary, the filtering function of the selfboundary and the mindful (from within) and the non-mindful dissociated (from outside the garden) perception of the other are specifically practised in pairs. These exercises allow participants to physically experience the interpersonal dynamics. Prior to the course, a preliminary conversation is held with each participant in which it is explained, among other things, that the training does not constitute therapy and cannot replace it and that the group is not a self-help group.

\section{Participants}

\section{MATERIALS AND METHODS}

A total of 44 people took part in SBAT over 5 separate courses. Two questionnaires were not filled in completely and could not be evaluated. Of the remaining 42 individuals, 32 were women and 10 were men, with an average age of 47 years (minimum 31 years/maximum 61 years). The courses were conducted by a psychiatrist or psychotherapist, together with a psychologist or psychotherapist in 2 of the 5 instances and with a body therapist in 1 instance. 


\section{Questionnaires}

The participants were given the FMI and BPS-14 questionnaires on the first course evening and were requested to fill them in on the same day or the day after. At the end of the 8-week course they were given the same two questionnaires again.

\section{Freiburg Mindfulness Inventory (FMI)}

The short version (14 items) of the Freiburg Mindfulness Inventory developed by Walach and Buchfeld was used (Buchfeld 2001, 2002, Walach 2004). The FMI measures self-assessment of mindfulness with a scale for presence and one for acceptance. When answering the questionnaire there are 4 possible responses available (rarely, occasionally, fairly often and almost always), with corresponding scores from 1 to 4 . It must be noted that question 13 is negatively framed, and the scoring must therefore also be reversed. The questionnaire has been thoroughly validated and has high internal consistency with a Cronbach's $\alpha$ of 0.87 (Walach 2004).

\section{Boundary Protection Scale (BPS-14)}

The validated BPS questionnaire was developed to measure mental self-protection for use in the therapeutic setting as well as for research purposes (Blaser 2014b). The questionnaire investigates various functions of the mental self-boundary, such as permeability, unwanted burdening, maintaining one's own energy, being able to dwell mentally within one's own mental self-boundaries and self-protection. There are 5 possible responses available (almost never, rarely, occasionally, frequently and almost always), which are scored from 1 to 5 in the same order, although it must be noted that questions 6 to 9 are reversed and must therefore be scored in reverse. The questionnaire has high internal consistency with a Cronbach's $\alpha$ of 0.79 (Blaser 2014b).

\section{Results}

A paired -sample t-test with repeated measurements was carried out in order to investigate the effect of the 8-week SBAT on the participants' capacity for mindfulness and protection of their own boundaries. For this purpose, the Freiburg Mindfulness Inventory (FMI) and Boundary Protection Scale (BPS-14) were administered to participants once before the course and once after the 8-week course (N SBAT=42).

\section{FMI}

Evaluation of the FMI results demonstrates that SBAT improves the capacity to perceive current events more mindfully and to dwell in the present (see table 3 and figure 2). A pairedsamples t-test was conducted to evaluate the impact of the 8-week SBAT on the participants scores on the FMI. There was a statistically significant higher Mindfullness score at the end of the training session (Mbefor $=36.88, \mathrm{SD}=5.17$; Mafter=41.98, $\mathrm{SD}=4.36$ ), $\mathrm{t}(41)=-7.53, \mathrm{p}<.0005$ (two-tailed). The 95\% confidence interval ranging from -6.46 to -3.73 . the eta squared statistic (.58) indicated a large effect size.

\section{BPS}

There was a significant improvement in the participants' ability to protect their own boundaries (see table 3 and figure 2). The Results of the paired-samples t-test indicate a statistically significant increase in the ability to protect their own boundaries. Mbefor $=40.88$, $\mathrm{SD}=6.91 ;$ Mafter $=33.04, \mathrm{SD}=5.95, \mathrm{t}(41)=8.91 ; \mathrm{p}<.0005$ (two-tailed). The eta squared statistic (.66) shows a large effect size. 
Table 3: Means (M) and standard deviations (SD) before and after Self-Boundary Awareness Training, $\mathrm{N}=42$

\section{BPS}

\section{FMI}

\begin{tabular}{|c|c|c|c|c|c|}
\hline & & $\mathrm{M}$ & (SD) & $\mathrm{M}$ & (SD) \\
\hline $\begin{array}{l}\text { Before } \\
\text { training }\end{array}$ & & 40.88 & (6.91) & 36.88 & (5.17) \\
\hline $\begin{array}{l}\text { After } \\
\text { weeks } \\
\text { training }\end{array}$ & $\begin{array}{c}8 \\
\text { of }\end{array}$ & 33.04 & (5.95) & 41.97 & $(4.36)$ \\
\hline
\end{tabular}

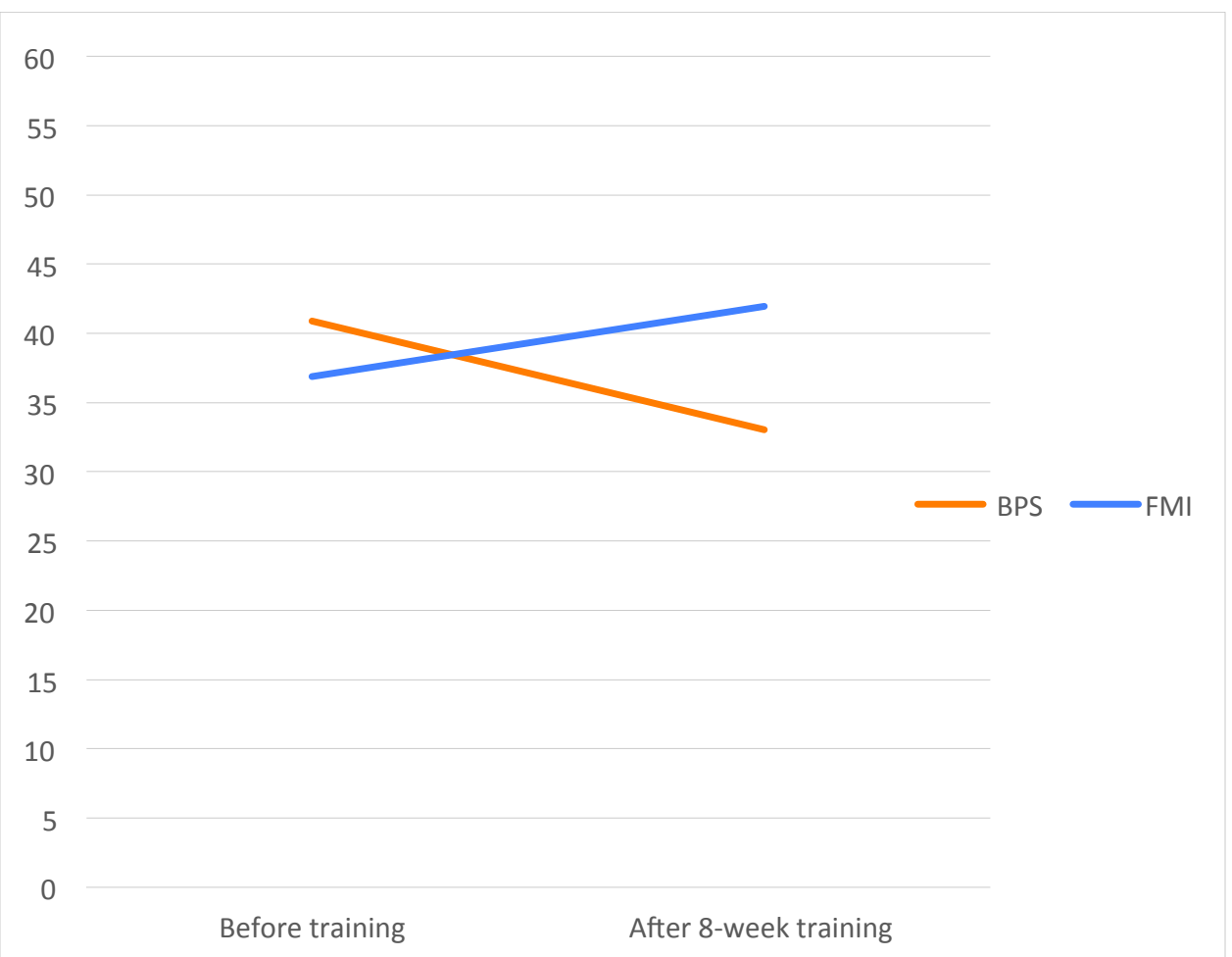

Fig. 2: Changes in mindfulness and boundary protection. The lower the score on the BPS-14, the better the boundary awareness. The higher the score on the FMI, the greater the mindfulness.

\section{DISCUSSION}

A structured, 8-week course to strengthen the mental self-boundary leads not only to a clear improvement on the BPS-14 but also a significant increase in the FMI score. Remarkable is that the improvement on the FMI was able to be achieved without the body scan, sitting meditation, yoga exercises or other mindfulness exercises.

This raises several interesting questions. Firstly, how can the relationship between the mental self-boundary and mindfulness be explained? Secondly, how can the efficacy of SBAT with regard to mindfulness be understood when SBAT does not involve any breathing exercises, yoga or body scan such as in MBSR or other mindfulnesstechnics? As already mentioned in the Introduction, in mindfulness, perception of the inner mental world and the inner orientation are fundamental. Different perceptions of the inner world are often described as a consequence of mindful perception. Is the aspect of attention to the current moment the consequence of a mindful mental state or a precondition? Further research into this question is planned. 
Blaser, K. \& Buchli-Kammermann, J. (2017). Training to Strengthen the Mental Self-boounary (Self-Boundary Awareness Training, SBAT) results in Greater Mindfulness: How Self-Boundary Awareness Increases Mindfulness. Advances in Social Sciences Research Journal, 4(1) 62-71.

How comes that an attentionlocation in the inner world leads automatically to a benevolent acceptance of another person? Presumably, practising a friendly, benevolent attitude does not, conversely, always lead to mindfulness. In many mindfulness exercises, directing the attention to the body helps to anchor the individual in the present experience and thus also facilitates non-identification with emotions (Walach 2004).

The exercises in SBAT do not primarily involve the body. There are no breathing, yoga or body scan exercises; instead, self-perception is trained with the use of images. Questions such as where am I dwelling with the location of my attention in this moment are answered both mentally and through the individual's immediate sensations. For example, if a participant does not perceive any subtle physical sensations (no "felt sense") in the moment of pausing, they know they are located with their attention in the extrapersonal space and are thus presumably not in a mindful state. If, on the other hand, they sense a pleasant warmth in their abdomen, for example, they are physically connected with themselves and thus located with their attention in their inner world.

In this manner, participants in the SBAT course learn to distinguish between being with the attentionlocation within the inner world or being outside the "mental garden". SBAT can be described as an operationalized shifting in the focus on the self from different perspectives. Once arrived in their inner world and that is noteworthy, they notice that they now perceive their fellow humans with a gentleness and unifying love. By becoming conscious of different mental locations of attention and perspectives with regard to their own inner mental world and that of others, as well as the respective qualities of perception, their mindfulness is presumably enhanced. The latter possibly also has to do with the fact that the effect of increased mindfulness, or, in other words, dwelling more frequently and for longer periods in one's own inner world, is perceived as pleasant and leads to heightened body awareness (Carmody 2008). This in turn leads to beneficial emotion regulation (Bechara 2004, Damasio 2003). Situations and events, as well as other people and objects, are perceived differently from within the inner world than from the cognitively determined extrapersonal space. This reappraisal is typical for newly acquired mindfulness (Garland 2011). Increased parasympathetic tone and decreased sympathetic nerve activity, both of which are associated with mindfulness (Benson 2000) and are accompanied by reduced blood pressure (De la Fuente 2010) and decreased cortisol levels (Carlson 2007), presumably also have an important effect on the well-being of the mindful individual. However, these physical reactions can also be understood as a response to improved self-protection and as feeling secure with a healthy, protective self-boundary.

It can thus be expected that due to conscious protection of the innerworld following SBAT, external stress factors will have less of a negative impact. However, there have not yet been any studies to support this conjecture. In addition, it is likely that the protective effect of a healthy mental self-boundary after an 8-week SBAT course could also have a positive impact in certain psychological disorders, e.g. social phobias and post-traumatic disorders (in which the self-boundary is likely to be partially destroyed; Blaser, 2011).

As SBAT enables participants to consciously occupy various interpersonal perspectives, it is also conceivable that for individuals who suffer from a personality disorder with healthy or pathological dissociative symptoms, moving closer to their own inner world and consciously entering their own inner world and that of others could lead to an alleviation of their symptoms. Further studies would be desirable. 
Finally, there is the question of which indications SBAT is appropriate for, particularly given that this initial study demonstrates efficacy with regard to mindfulness.

In conclusion, it can be said that SBAT not only improves self-protection, enhances selfboundary awareness and increases the flexibility of different interpersonal attentions, it also causes a significant increase in mindfulness.

\section{References}

Bechara, A., Naqvi, N. (2004). Listening to your heart: Interoceptive awareness as a gateway to feeling. Nature Neuroscience, 7, 102-103.

Benson, H. (2000). The Relaxation Response. New York: Harper.

Blaser, K. (2015). No empathy without self-boundaries: A new spatial attention concept for understanding empathy. J. Studies in Social Sciences, 12(2), 219-234.

Blaser, K., Zlabinger, M.,Hautzinger, M., Hinterberger, T. (2014a). Das interpersonelle AufmerksamkeitsManagementinventar: ein neues Instrument zur Erfassung unterschiedlicher Selbst- und Fremdwahrnehmungsfähigkeiten. Zeitschrift Forschende Komplementärmedizin 21, 34-34.

Blaser, K., Zlabinger, M., Hautzinger, M., Hinterberger, T. (2014b). The relationship between mindfulness and the mental self-boundary: validation of the boundary protection scale-14 (BPS-14) and its correlation with the Freiburg Mindfulness Inventory (FMI). J. Educ. Dev. Psychol. 4, 155-162.

Blaser, K. (2013). Intra- and interpersonal mindful and non-mindful mental states: comparison of a new spatial attention concept and the IAA mindfulness model of Shapiro. Mindfulness, 4, 64-70.

Blaser, K. (2012). Aufmerksamkeit und Begegnung: Zwischenmenschliches Aufmerksamkeitsrepertoire, IchGrenzen und die Kunst des Zusammenseins. (Attention and Encounters: Interpersonal Attention Repertoire, the Self-Boundary and the Art of Being Together). Kröning: Asanger Verlag.

Blaser, K. (2011). Boundary based Awareness und transgenerationale Traumaweitergabe. Zeitschrift für Psychotraumatologie, Psychotherapiewissenschaft, Psychologische Medizin, 75-81.

Borkovec, T.D. (2002). Life in the future versus life in the present. Clinical Psychology: Science and Practice, 9, $76-$ 80.

Buchheld, N., Grossman, P., Walach, H. (2001). Measuring mindfulness in insight meditation (Vipassana) and meditation-based psychotherapy: The development of the Freiburg mindfulness inventory (FMI). J. Meditation Res., 1, 11-34.

Buchheld, N., Walach, H. (2002). Achtsamkeit in Vipassana-Meditation und Psychotherapie. Die Entwicklung des "Freiburger Fragebogens zur Achtsamkeit". Zeitschrift für Klinische Psychologie, Psychiatrie und Psychotherapie, 50, 153-172.

Carlson, L.E., Speca, M., Faris, P., Patel, K.D. (2007). One year pre-post intervention follow-up of psychological, immune, endocrine and blood pressure outcomes of mindfulness-based stress reduction (MBSR) in breast and prostate cancer outpatients. Brain, Behaviour and Immunity, 21, 1038-1049.

Carmody, J., Baer, R.A. (2008). Relationships between mindfulness practice and levels of mindfulness, medical and psychological symptoms and well-being in a mindfulness-based stress reduction program. J.Behavioral Medicine, 31, 23-33.

Damasio, A. (2010). Self Comes to Mind. Constructing the Conscious Brain. New York: Pantheon Books.

Damasio, A.R. (2003). Looking for Spinoza: Joy, Sorrow, and the Feeling Brain. New York: Harcourt.

De la Fuente, M., Franco, C., Salvator, M. (2010). Reduction of blood pressure in a group of hypertensive teachers through a program of mindfulness meditation. Behavioral Psychology/Psicologia Conductual, 18, 533-552.

Freud, S. (1958). Beyond the pleasure principle. In S. J. London (Ed). In the Standard Edition of the complete psychological works of Sigmund Freud. London: Hogarth Press, vol. 18,

$(7-64)$. 
Blaser, K. \& Buchli-Kammermann, J. (2017). Training to Strengthen the Mental Self-boounary (Self-Boundary Awareness Training, SBAT) results in Greater Mindfulness: How Self-Boundary Awareness Increases Mindfulness. Advances in Social Sciences Research Journal, 4(1) 62-71.

Farb, N.A.S., Segal, Z.V., Mayberg, H., Bean,J., McKeon, D., Fatima, Z., Anderson, A.K. (2007). Attending to the present: Mindfulness meditation reveals distinct neural modes of self-reference. Social cognitive and affective neuroscience, 2, 313-322.

Fuchs, T. (2008). Das Gehirn - ein Beziehungsorgan: Eine phänomenologisch-ökologische Konzeption. Stuttgart: Kohlhammer.

Gallese, V. (2009). Die geteilte Mannigfaltigkeit. In: Metzinger, T.: Der Ego-Tunnel. Eine neue Philosophie des Selbst. Von der Hirnforschung zur Bewusstseinsethik. Berlin: Berlin Verlag.

Garland, E.L., Gaylord, S.S., Frerickson, B.L. (2011). Positive reappraisal mediates the stress-reductive effects of mindfulness: An upward spiral process. Mindfulness, 2, 59-67.

Gendlin, E.T. (1998). Focusing-Oriented Psychotherapy: A Manual of the Experiential Method. New York: The Guilford Press.

Gunaratana, H. (1992). Mindfulness in Plain English. Boston: Wisdom Publications.

Hanh, T.N. (1999). The Heart of Buddha's Teaching. New York: Broadway.

Hayes, S.C., Strosahl, K.D., Wilson, K.G. (1999). Acceptance and Commitment Therapy: An Experiential Approach to Behaviour Change. New York: Guilford Press.

Hinterberger, T., Zlabinger, M., Blaser, K. (2014). Neurophysiological correlates of various mental perspectives. Frontiers in Human Neuroscience, 8(637), 1-16.

Hölzel, B.K., Lazar, S.W., Gard, T., Schuman-Olivier, Z., Vago, D.R., Ott, U. (2011). How does mindfulness meditation work? Proposing mechanism of action from a conceptual and neural perspective. Perspectives on psychological science, 6 (6), 537-559.

Husserl, E. (2002). Phänomenologie der Lebenswelt: Ausgewählte Texte II. Stuttgart: Reclam.

Kabat-Zinn, J. (1990). Full Catastrophe Living. Using the Wisdom of Your Body and Mind to Face Stress, Pain, and Illness. New York: Random House.

Kabat-Zinn, J., (2003). Mindfulness based interventions in context: Past, present and future. Clin. Psych. Science and Practice, 10(2), 144-156.

Kerr, C.E., Josyula, K., Littenberg, R. (2011). Developing an observing attitude: An analysis of meditation diaries in an MBSR clinical trial. Clinical psychology \& psychotherapy, 18, 80-93.

Lazar, S.W. (2005). Mindfulness research. In: Germer, C.K., Siegel, R.D., Fulton, P.R. (eds): Mindfulness and Psychotherapy. New York: Guilford Press, 220-239.

Leary, M.R., Tauney, J.P. (2012). The self as an organizing construct in the behavioural and social sciences. In: Leary, M.R., Tauney, J.P. (eds): Handbook of Self and Identity. New York: Guilford Press, 1-21.

Linehan, M.M. (1993). Cognitive Behavioural Treatment of Borderline Personality Disorder. New York: Guilford Press.

Maslow, A. (1970). Motivation and Personality (2nd edition). New York: Harper \& Row.

Metzinger, T. (2009). The Ego Tunnel. The Science of the Mind and the Myth of the Self. New York: Basic Books.

Merleau-Ponty, M. (1966). Phänomenologie der Wahrnehmung. Berlin: Walter de Gruyter \& Co.

Northoff, G. (2007). Psychopathology and pathophysiology of the self in depression - neuropsychiatric hypothesis. Journal of Affective Disorders, 104, 1-14.

Preston S.D., de Waal, F.B.M. (2002). Empathy: Its ultimate and proximate bases. Behav. Brain Sci., 25, 1-72.

Rogers, C.R. (1961). On Becoming a Person. Boston: Houghton Mifflin.

Segal, Z.V., Williams, J.M.G., Teasdale, J.D. (2002). Mindfulness-Based Cognitive Therapy for Depression: A New Approach to Preventing Relapse. New York: Guilford Press.

Shapiro, S.L., Carlson, L.E., Astin, J.A., Freedman, B. (2006). Mechanisms of mindfulness. J. Clinical Psychology, 62(3), 373-386.

Siegel, D.J. (2007). Mind Your Brain. New York: W.W. Norton \& Company. 
Siegel, D. (2012). Pocket Guide to Interpersonal Neurobiology: An Integrative Handbook of the Mind. New York: W.W. Norton \& Company.

Stierlin, H. (1978). Delegation und Familie: Beiträge zum Heidelberger Familien dynamischen Konzept. Frankfurt am Main: Suhrkamp Verlag.

Tausk, V. (1992). On the origin of the "influencing machine". J. Psychotherapy Practice and Research, 1, $184-206$.

Thera, N. (1962). The Heart of Buddhist Meditation. New York: Weiser.

Walach, H., Buchheld, N., Buttenmüller, V., Kleinknecht, N., Grossman, P., Schmidt, S. (2004). Empirische Erfassung der Achtsamkeit - die Konstruktion des Freiburger Fragebogens zur Achtsamkeit (FFA) und weitere Validierungsstudien. In: Heidenreich, T., Michalak, J. (Ed.): Achtsamkeit und Akzeptanz in der Psychotherapie. Tübingen: Deutsche Gesellschaft für Verhaltenstherapie, 727-770.

Winnicott, D.W. (1965). Counter-Transference in the Maturational Processes and the Facilitating Environment: Studies in the Theory of Emotional Development. New York: International Universities Press. 